\title{
Risk Classification in an Emergency Room: Agreement Level Between a Brazilian Institutional and the Manchester Protocol ${ }^{1}$
}

\author{
Cristiane Chaves de Souza ${ }^{2}$ \\ Alexandre Duarte Toledo ${ }^{3}$ \\ Luiza Ferreira Ribeiro Tadeu ${ }^{4}$ \\ Tânia Couto Machado Chianca ${ }^{5}$
}

\begin{abstract}
The aim of this study was to assess the level of agreement between an institutional protocol and the Manchester protocol for the risk assessment of patients attended in an emergency room of a public hospital in Belo Horizonte - MG - Brazil. This is a descriptive and comparative study, in which 382 patients' reports were evaluated and the risk was classified, using the institutional protocol and the Manchester protocol. Rates were calculated through weighted and unweighted kappa, in order to determine the level of agreement between the protocols. The results showed that the correlation between the protocols is average when considering that classification errors occurred between neighboring colors (kappa $=0.48$ ), and good when considering that classification errors occurred between extreme colors (kappa=0.61). The Manchester protocol increased the patients' level of priority of patients and has been considered more inclusive.
\end{abstract}

Descriptors: Nursing; Emergency Medical Services; Triage.

\footnotetext{
${ }_{1}^{1}$ Paper extracted from Master's Dissertation "Grau de concordância da classificação de risco de usuários atendidos em um Pronto Atendimento utilizando dois diferentes protocolos" presented to Programa de Pós-Graduação em Enfermagem, Escola de Enfermagem, Universidade Federal de Minas Gerais, MG, Brazil.

2 RN, M.Sc. in Nursing, Hospital Municipal Odilon Behrens, Belo Horizonte, MG, Brazil. E-mail: Cristiane - souzac.cris@gmail.com, Alexandre - alexandreenfermeiro@yahoo.com.br.

${ }^{3}$ Nursing undergraduate student, Escola de Enfermagem, Universidade Federal de Minas Gerais, MG, Brazil. Scholarship holder, Scholarship holder at the Fundação de Amparo à Pesquisa do Estado de Minas Gerais (FAPEMIG), MG, Brasil. E-mail: luizafrt@gmail.com.

${ }^{4}$ RN, Ph.D. in Nursing, Associate Professor, Escola de Enfermagem, Universidade Federal de Minas Gerais, MG, Brazil. E-mail: tchianca@enf.ufmg.br.
}

Corresponding Author:

Cristiane Chaves de Souza

Universidade Federal de São João del Rei. Curso de Enfermagem.

Rua Sebastião Gonçalves Coelho, 400

Bairro Chanadour

CEP: 35501-293 Divinópolis, MG, Brasil

E-mail: souzac.cris@gmail.com 


\title{
Classificação de risco em pronto-socorro: concordância entre um protocolo institucional brasileiro e Manchester
}

Este estudo teve por objetivo verificar o grau de concordância entre um protocolo institucional e o protocolo de Manchester, para a classificação de risco de pacientes atendidos no pronto-socorro de um hospital público de Belo Horizonte, MG, Brasil. Tratase de estudo descritivo comparativo, no qual 382 prontuários foram avaliados e realizada a classificação de risco, utilizando os protocolos mencionados acima, a partir do registro realizado pelos enfermeiros. Índices Kappa ponderado e não ponderado foram calculados para determinar o grau de concordância entre os protocolos. Os resultados mostraram que a concordância entre os protocolos é média, quando considerados os erros de classificação, ocorridos entre cores vizinhas (Kappa=0,48) e boa, quando considerados os erros de classificação, ocorridos entre cores extremas (Kappa=0,61). Conclui-se que o protocolo de Manchester aumentou o nível de prioridade dos pacientes, demonstrando ser protocolo mais inclusivo.

Descritores: Enfermagem; Serviços Médicos de Emergência; Triagem.

\section{Clasificación de riesgo en primeros auxilios: concordancia entre un protocolo institucional brasileño y el de Manchester}

\begin{abstract}
Este estudio tuvo por objetivo verificar el grado de concordancia entre un protocolo institucional y el protocolo de Manchester para la clasificación de riesgo de pacientes atendidos en primeros auxilios de un hospital público de Belo Horizonte - MG - Brasil. Se trata de estudio descriptivo comparativo en el cual 382 fichas fueron evaluadas $y$, realizada la clasificación de riesgo utilizando los protocolos mencionados encima, a partir del registro realizado por los enfermeros. Índices kappa ponderado y no ponderado fueron calculados para determinar el grado de concordancia entre los protocolos. Los resultados mostraron que la concordancia entre los protocolos es media, cuando considerados los errores de clasificación ocurridos entre colores vecinos (kappa=0,48) y buena, cuando considerados los errores de clasificación ocurridos entre colores extremos (kappa $=0,61$ ). Se concluye que el protocolo de Manchester aumentó el nivel de prioridad de los pacientes, demostrando ser un protocolo que incluye más.
\end{abstract}

Descriptores: Enfermería; Servicios Médicos de Urgencia; Triaje.

\section{Introduction}

Urgency and emergency services represent an important component of Brazilian healthcare. In recent years, the demand for urgency and emergency care has increased, mainly due to the increase in the number of accidents and urban violence. The reality of overloaded Brazilian emergency care units is aggravated by organizational problems, such as attendance in order of arrival without establishing clinical criteria, which can entail severe damage for patients ${ }^{(1)}$.

Aware of existing problems in the urgency area, in 2004, the Brazilian Ministry of Health launched the
National Humanization Policy Folder, in which welcoming with assessment and risk classification is appointed as a device to change health care work and production, particularly at urgency services. Risk classification is a dynamic process of identifying patients who need immediate treatment, according to the potential risk, health problems or degree of suffering. Care should be prioritized in line with the severity of the patient's clinical condition, instead of the order of arrival at the service(2).

Nurses have been indicated as professionals to assess and classify the risk of patients attending 
urgency services, and should follow a guiding protocol(3). In general, the use of scales/protocols has been recommended which rank risks in five levels, as these display better reliability, validity and trustworthiness levels to assess the patient's clinical condition(4). Among these scales/protocols, the following can be mentioned: the North American scale - "Emergency Severity Index (ESI)"; the Australian scale - "Australasian Triage Scale (ATS)"; the Canadian protocol - "Canadian Triage Acuity Scale $\left(\mathrm{CTAS}^{\odot}\right)^{\prime}$ " and the British protocol - "Manchester Triage System" - Manchester Protocol(5). Besides these, other protocols have been developed, such as the protocol of Hospital Municipal Odilon Behrens - HOB Minas Gerais, Brazil(6), which was based on preexisting scales and protocols, using the Canadian data collection method. The HOB was the first hospital in Minas Gerais that put in practice risk classification and serves as a Brazilian reference for the use of this device.

Today, the Brazilian Ministry of Health have attempted to standardize the welcoming process with risk classification by adopting measures that unify this process across the national territory(7). In this sense, in Minas Gerais, technological modernization and the implantation of the computerized Manchester protocol were chosen to guide risk classification at all urgency services in the State. In some institutions, however, especially the $\mathrm{HOB}$, a protocol constructed by the hospital team was already being used.

Some authors affirm that there is no standard protocol in health measurement ${ }^{(8)}$. Measurement demands indicators that represent a concept. There is no infallible measurement instrument. Instead, situational and environmental factors, tendentiousness in answers, personal factors and alterations in the data collection method can contribute to measurement errors ${ }^{(9)}$. When using instruments from another language, cross-cultural adaptation is needed, even when the language is the same, as problems can arise in the cultural adaptation process. In this process, some items can be changed to maintain the same concept, and there is not much clarity as to how much of the original measurement properties are maintained in the adapted instrument ${ }^{(10)}$.

The clinical patient risk classification criteria established in both protocols ( $\mathrm{HOB}$ and Manchester) include the priority levels and color attributed, the waiting time for medical attendance, nursing re-assessment and the method to assess the main complaint, layering the risk in five distinct levels which have been indicated by colors for the sake of easier visualization. Differences between both protocols exist, however, especially regarding waiting time for medical attendance, time for nursing re-assessment (not included in the Manchester Protocol), the method to assess the main complaint, layered through flowcharts in the HOB Protocol and symptoms in the Manchester Protocol. Thus, at this moment of putting in practice a new protocol to replace a preexisting one, a comparative study is needed between the two protocols for patient classification at urgency and emergency units.

It is known that the Manchester Protocol is used in many countries for patient risk classification at emergency and urgency services and that, before deciding on its practice at institutions in Minas Gerais state, a group of Brazilian specialists assessed the feasibility of adapting this protocol to the Brazilian reality. There is no research, however, on differences in risk classification results when using the Manchester Protocol and other local protocols like the HOB. Until date, no publications were found on the validation of the Manchester Protocol in Brazil within criteria established in literature. Hence, this study was designed to verify the agreement level between the HOB and Manchester Protocols for risk classification of users attended at the HOB emergency unit.

\section{Method}

This descriptive and comparative study was carried out at the HOB. The hospital is part of the Belo Horizonte municipal health network.

The study population comprised 339,133 care forms, corresponding to all files of patients attended at the HOB emergency unit since Welcoming with Risk Classification was put in practice (September $22^{\text {nd }} 2005$ ) until September 22 nd 2007. Patient files were included when the users went through risk classification and the files contained records that identified the nursing professional who delivered care and described the evaluation and the classification the user received.

The sample contained 382 files. Sampling was based on simple randomization of the files and an electronic draft of the patient record numbers. Stat Calc, Epi Info software, version 3.4.1 was used for sample calculations. The expected minimal agreement level between the two protocols was set at $80 \%$, with an acceptable error margin of $5 \%, 95 \%$ confidence level and $5 \%$ loss rate.

For data collection, documentation in the drafted files were subject to content analysis, seeking the following data: complaints the patient presented, vital 
data, previous history, age and risk classification at the end of the assessment carried out by the nurse. The complaints were literally transcribed in a Word document, in the form of clinical cases, so that the patients' risk classification could be redone according to the $\mathrm{HOB}$ and Manchester Protocols. The patients' re-classification according to the HOB Protocol was done manually. For the Manchester Protocol, the risk classification software was used with the computerized protocol. Criteria were set for comparison between the priority levels and color standard for both protocols. Thus, color red II in the $\mathrm{HOB}$ Protocol was considered orange, in view of existing correspondence between the priority levels in both protocols.

For data analysis, SPSS (version 17.0) and R (version 2.7.1) statistical software was used. Descriptive analysis was carried out, and sensitivity and specificity measures were calculated for each classification level. The agreement level between the risk classification according to the HOB and Manchester protocol was measured by Cohen's Kappa ratio. Kappa ratios between 0 and 0.20 were considered bad agreement; between 0.21 and 0.40 weak agreement, between 0.41 and 0.60 average agreement; between 0.61 and 0.80 good agreement; between 0.81 and 1 excellent agreement. At a $95 \%$ confidence interval, the weighted Kappa ratio was calculated to analyze general agreement between the two protocols, as well Kappa not weighted by color, in order to identify the main points of agreement and disagreement between the protocols(11). In addition, sensitivity and specificity ratios were calculated for each classification level. Sensitivity ratios were calculated to evidence the probability that a user classified at a given risk according to the $\mathrm{HOB}$ protocol would be classified at the same priority level according to the Manchester protocol. Specificity was used to evidence the probability that users who were not classified at a given risk level according to the $\mathrm{HOB}$ protocol were not classified at the same risk level either when using the Manchester protocol.

To check for the existence of correlation and its strength between the patient's age and the attributed risk classification level, Spearman's non-parametric correlation test and the linear regression analysis tests were used, respectively. To analyze the influence of vital data on risk classification according to both protocols, the Mann-Whitney test was used. The variables that were compared were the risk classification, using the two protocols (ordinal categorical variable) between the two independent groups (patient files with complete records of vital data and without complete records of vital data).

This research complied with National Health Council Resolution 196/96 on research involving human beings. Approval was obtained from the Research Ethics Committee at UFMG (COEP-UFMG - Opinion Etic No529/08), from the Superintendence and Research Ethics Committee at Hospital Municipal Odilon Behrens, and from the company ALERT ${ }^{\circledR}$, which holds the copyright of the Portuguese Screening Group for the trading and use of the Manchester Protocol.

\section{Results}

Out of 204 patients, the majority (53.4\%) was female, with a mean age of 39.32 years (minimum 13 and maximum 89; median 36 and $S D=17.38$ years).

According to the nomenclature of the HOB protocol, a range of patient complaints is perceived, including urgent complaints related to respiratory failure, digestive hemorrhage, acute hemiparesis, severe abstinence from alcohol and drugs, convulsion and cranial trauma, besides non-urgent complaints (flue symptoms, light to moderate pain, vomiting and diarrhea without dehydration)

According to the Manchester protocol nomenclature, on the other hand, pain was the main patient complaint, with headache and abdominal pain corresponding to $31.5 \%$ of all complaints, followed by malaise in adults (14.0\%), thoracic pain (10.8\%) and limb problems (7.8\%).

According to the study protocols, risk classification per color permitted an analysis of the patients' distribution in absolute figures (Table 1).

Table 1 - Agreements and disagreements between HOB and Manchester protocols. Belo Horizonte, 2009

\begin{tabular}{|c|c|c|c|c|c|c|c|}
\hline \multirow{2}{*}{\multicolumn{2}{|c|}{ Protocol/Color }} & \multicolumn{5}{|c|}{ HOB Protocol } & \multirow{2}{*}{ Total } \\
\hline & & Red & Orange (Red II) & Yellow & Green & Blue & \\
\hline \multirow{5}{*}{ Manchester Protocol } & Red & 3 & 10 & 06 & 01 & 00 & 20 \\
\hline & Orange & 0 & 40 & 20 & 04 & 03 & 67 \\
\hline & Yellow & 0 & 07 & 38 & 20 & 01 & 66 \\
\hline & Green & 0 & 4 & 41 & 98 & 36 & 179 \\
\hline & Blue & 0 & 01 & 4 & 04 & 03 & 12 \\
\hline \multicolumn{2}{|l|}{ Total } & 3 & 62 & 109 & 127 & 43 & 344 \\
\hline
\end{tabular}

Source: Patient files attended in HOB risk classification between Sept/05 and Sept/07. 
It should be highlighted that, in 38 cases, the classification could not be accomplished by both protocols, as these flowcharts contained no guiding elements compatible with the main complaints that were described, which is why they were removed from the agreement analysis. In all cases that could not be reclassified, the main complaint was not well described, with a lack of records on the start, intensity and duration of the symptoms.

To assess the general agreement level between the two protocols, the Kappa ratio with linear and squared weighting was calculated. The Kappa ratio with global linear weighting equaled 0.48 , against 0.61 with squared weighting, based on which it can be inferred that the agreement level is average when considering disagreements between neighboring colors, and good when considering disagreements between extreme colors.

The analysis of agreement level per color (Table 2) revealed average agreement between the protocols for patients classified as orange (Kappa=0.53), followed by weak agreement for patients classified as green $($ Kappa $=0.37)$, yellow $($ Kappa $=0.26)$, red $($ kappa $=0.25)$ and bad agreement for blue (kappa=0.06).

Table 2 - Unweighted Kappa Ratios, sensitivity and specificity in each classification color according to $\mathrm{HOB}$ protocol and Manchester protocol. Belo Horizonte, 2009

\begin{tabular}{lccc}
\hline \multicolumn{1}{c}{ Classification Color } & Kappa Ratio & Sensitivity & Specificity \\
\hline Red & 0.25 & 1 & 0.95 \\
Orange & 0.53 & 0.65 & 0.90 \\
Yellow & 0.26 & 0.35 & 0.88 \\
Green & 0.37 & 0.77 & 0.63 \\
Blue & 0.06 & 0.07 & 0.97 \\
\hline
\end{tabular}

Source: Patient files attended in HOB risk classification between Sept/05 and Sept/07.

At priority level I, represented by the color red, the agreement level was weak, although sensitivity equaled 1. This guarantees that all patients classified as red by the HOB protocol would also be classified as such by the Manchester protocol. In view of a 0.95 specificity level, it can be affirmed that patients not classified as red by the HOB protocol would not be classified as red either by the Manchester protocol.

In orange, the agreement level between the protocols was medium (kappa $=0.53$ ), with $65 \%$ of patients classified as orange by both protocols. In view of a 0.65 sensitivity level, it can be affirmed that patients classified as orange by the HOB protocol would also be classified as orange by the Manchester protocol, and that patients not classified as orange by the $\mathrm{HOB}$ protocol would not be classified as such either by the Manchester protocol, with sensitivity equaling 0.90 . Among patients classified as orange by both protocols, $82.5 \%$ manifested some type of pain, and "intense pain" findings were definitive for agreement levels on the color orange in the patients' classification.

In yellow, the agreement level between both protocols was weak, with kappa equaling 0.26. Among the 109 patients classified as yellow by the $\mathrm{HOB}$ protocol, only $35 \%$ were also classified as such by the Manchester protocol. At a low sensitivity level of 0.35 , one may say that patients classified as yellow by the HOB protocol would also be classified as yellow by the Manchester protocol. At a specificity level of 0.88 , patients not classified as yellow by the HOB protocol would not be classified as such either by the Manchester protocol. Among patients showing agreement between classifications, the discriminator "warm adult" was the determinant element for classification under yellow in both protocols. The specific discriminators "moderate pain" (5-13.2\%), "pleuritic pain" (5-13.2\%) and "colic" (3-7.9\%) were also important to determine classification at this level.

At priority level IV (green color), the agreement level between the protocols was also weak (kappa=0.37). Out of 127 patients classified as green by the HOB protocol, $77 \%$ were also classified as green by the Manchester protocol. It can be affirmed that a patient classified as green by the HOB protocol would also be classified as green by the Manchester protocol (Sensitivity $=0.77$ ) and that a patient not classified as green by the $\mathrm{HOB}$ protocol would not be classified at this priority level either by the Manchester protocol (Specificity $=0.63$ ).

The agreement level on patients classified as blue was the lowest of all (Kappa=0.06). Out of 43 patients classified as blue by the HOB protocol, only 3 (7\%) were classified as such by the Manchester protocol. Therefore, for the study sample, it can be affirmed that patients not classified as blue by the HOB protocol would not be classified as blue by the Manchester protocol (Specificity $=0.97$ ), and that patients classified as blue by the HOB protocol are also classified as such by the Manchester protocol (Sensitivity $=0.07$ ).

Regarding the analysis of how age influences risk classification, Spearman's non-parametric correlation test showed, at a $5 \%$ significance level, that age is associated with risk classification $(r=0.1 ; p=0.04)$ for the HOB protocol. On the other hand, the linear 
regression analysis showed that the strength of the association between age (predictive variable) and risk classification is very small and showed to be insignificant to change the risk level attributed in clinical practice. According to Spearman's non-parametric correlation test, no significant association was found between risk classification according to the Manchester protocol and the patients' age $(r=0.09$ and $p=0.10)$.

The results of the Mann-Whitney test indicated no association between the complete recording of vital data and the risk classification. P-values corresponded to 0.53 and 0.30 for the $\mathrm{HOB}$ and Manchester protocols, respectively.

The results of the Mann-Whitney test demonstrated a significant association between risk classifications according to the HOB protocol for patients whose files contained complete records on the main complaint in comparison with those showing incomplete data $(p$-value $=0.002)$. Priority levels were higher among patients in the group with a complete description of the main complaint assessment. No statistically significant association was found in the attributed risk classification between the group with and without complete records on the main complaint ( $p$-value=0.94) in the risk classification according to the Manchester protocol.

\section{Discussion}

The main complaints the patients in this study presented during the risk classification confirm literature findings about emergency hospitals delivering care to truly urgent as well as non-urgent cases. It should be highlighted, however, that the concept of urgency and emergency can differ in users and health workers' view. The population in general cannot distinguish between urgency and emergency ${ }^{(12)}$. Health professionals appoint divergences between the health needs that make users turn to the urgency unit and the work goal at this site, revealing dissatisfaction with patients' excessive demands, whose needs can be classified as urgency or emergency(13). Thus, some authors highlight the need for public policy strategies to enhance the efficiency and quality of urgency services ${ }^{(14)}$.

The Manchester protocol increased the percentage of patients classified as red, orange and green by $4.4 \%$, $0.7 \%$ and $12 \%$, respectively, and raised the priority level of those classified as blue by $10.2 \%$ in comparison with the results of the risk classification according to the $\mathrm{HOB}$ protocol. This demonstrated that the Manchester protocol was more inclusive (Table 1 ). A study carried out to verify the association between classification according to the Manchester protocol and mortality and hospitalization rates at the urgency service showed that this protocol is a powerful tool to distinguish between patients with high and low mortality risks, as well as to distinguish between patients who will not need hospitalization and who should return home(15)

The analysis of the global agreement between the HOB and Manchester protocols shows a greater probability of classification "errors" between neighboring colors than between extreme colors. With a view to investigating nurses' accuracy for the risk assessment and classification according to the HOB protocol, a low accuracy level was found between service nurses' classification and standard protocol. Total agreement or disagreement was not found at any classification level when comparing the nurses' classifications with the institutional protocol(7). Reliability analysis among nurses was assessed when using the Manchester protocol, showing a kappa ratio between 0.40 and 0.80 , with a median ratio of 0.63 . The Manchester protocol is a reliable instrument for use at emergency departments ${ }^{(16)}$.

Based on literature findings, it can be inferred that the intra and inter-rater agreement levels are higher when using the Manchester protocol(17). It should be highlighted, however, that there are less studies assessing the HOB protocol than those assessing the Manchester protocol. These findings are attributed to the classification method inherent in each protocol. The Manchester protocol's arrangement in guiding flowcharts facilitates nursing assessment, turning the classification process more secure and neutral.

The Manchester protocol increases the number of patients classified as red, green and blue and decreases the priority of patients classified as orange and yellow when compared with each priority level based on the HOB protocol. Hence, when using the Manchester protocol, a decrease is observed in the priority levels of patients classified under orange and yellow to green and blue. This ratifies literature findings ${ }^{(17)}$.

The Manchester protocol is considered a sensitive tool to detect, at the entry door of the emergency services, patients who will need critical care. Based on the risk classification according to the Manchester protocol, $67 \%$ of patients admitted to critical care areas were classified as red or orange. The protocol showed defects, however, to detect the cases of patients whose clinical condition worsened after going through the risk classification ${ }^{(18)}$. This result underlines the need to constantly reassess patients after the risk classification, 
until treatment is administered to solve their problems.

Complete records on the main complaint influence the risk level patients are attributed when using the $\mathrm{HOB}$ protocol, with higher priority levels for patients with complete records on the main complaint. Based on this finding, it can be inferred that a complete assessment of the main complain raises the priority level patients are attributed, underlining the importance of nursing skills and competencies for the correct and complete assessment and description of the main complaint the patient presents at the time of welcoming and risk classification.

\section{Conclusion}

It can be concluded that the agreement between the protocols is average when considering the classification errors that occurred between neighboring colors, and good when considering classification errors between extreme colors. This was proven in the analysis on the agreement level at each classification level, in which most disagreements were related to neighboring higher or lower priority levels. In general, the Manchester protocol increased patients' priority level when compared with the HOB protocol. This shows that the Manchester protocol is more inclusive.

These study results indicate that the Manchester protocol is well adapted to the HOB reality and, as it has been used in a computerized way, future research on technology use by nurses responsible for risk classification and validation studies of the Manchester protocol should be carried out, as this new technology is being put in practice in Brazil, representing an area with a lack of research.

It is known that risk classification is a relatively new activity in Brazilian nursing activities, and that it has increasingly conquered its space. Thus, it is fundamental for schools to invest in the education of skilled professionals who can respond to market needs in this area. For nurses working with risk classification, skills for qualified listening, assessment, correct and detailed recording of the main complaint, teamwork, clinical reasoning and mental agility for decision making are essential, as well as knowledge on support systems in the care network with a view to responsible patient forwarding when necessary.

It can undoubtedly be affirmed that the use of protocols to support risk classification offers a legal framework for safe nursing work. It cannot be ignored, however, that this is a process of welcoming and classifying. It is important to highlight that listening is the principle and willingness to listen the requisite to start a welcoming relation with the user, as that is the only way to guarantee a humanized risk classification process, enhancing the population's access to health services, thus reaching the central goal of qualified care delivery to SUS users.

\section{Acknowledgements}

Acknowledgements to the company ALERT ${ }^{\circledR}$ for its collaboration in the development of this study.

\section{References}

1. Ministério da Saúde (BR). Política Nacional de Atenção as Urgências. Brasília (DF): Ministério da Saúde; 2006.

2. Ministério da Saúde (BR). HumanizaSUS - acolhimento com avaliação e classificação de risco: um paradigma ético-estético no fazer em saúde. Brasília (DF): Ministério da Saúde; 2004.

3. Conselho Regional de Enfermagem de Minas Gerais. Parecer Técnico n¹0, de 22 de fevereiro de 2007. Dispõe sobre a participação do enfermeiro na triagem de pacientes sem a presença de médicos especialistas. Belo Horizonte (MG): Conselho Regional de Enfermagem de Minas Gerais; 2007.

4. Goransson KE, Ehrenberg A, Marklund B, Ehnfors M. Accuracy and concordance of nurses in emergency department triage. Scand J Caring Sci. $2005 ; 19(4): 432-8$.

5. Grupo de Triagem de Manchester. Triagem do serviço de urgência. 2a ed. Portugal: BMJ Publishing; 2002.

6. Hospital Odilon Behrens. Protocolo de acolhimento com classificação de risco. Belo Horizonte (MG): Hospital Odilon Behrens; 2006

7. Toledo AD. Acurácia de enfermeiros na classificação de risco em unidade de pronto socorro de um hospital municipal de Belo Horizonte [tese de mestrado]. Belo Horizonte (MG): Escola de Enfermagem /UFMG; 2009. $138 \mathrm{p}$.

8. Mc Dowell I, Newel C. The theorical and technical foundations of health measurement. In: Mc Dowell I, Newel C. Measuring health: a guide to rating scales and questionnaires. New York (NY): Oxford University Press; 1987. p. 12-35.

9. Polit D, Hungler BP, Beck CT. Fundamentos de pesquisa em enfermagem. $5^{a}$.ed. Porto Alegre: Artmed; 2004. 487 p.

10. Guillemin F. Cross cultural adaptation and validation of health status measures. Scand J Rheumatol. $1995 ; 24(2): 61-3$. 
11. Landis JR, Koch GG. The measurement of observer agreement for categorical data. Biometrics. 1977;33(1):159-74.

12. Rocha AFS. Determinantes da procura de atendimento de urgência pelos usuários nas unidades de pronto atendimento da secretaria municipal de saúde de Belo Horizonte. [Dissertação]. Belo Horizonte (MG): Universidade Federal de Minas Gerais; 2005.

13. Garlet ER, Lima MADS, Santos JLG, Marques GQ. Finalidade do trabalho em urgências e emergências. Rev. Latino-Am. Enfermagem [internet]. 2009 [acesso em: 06 abril 2010];17(4):535-40. Disponível em: http://www. scielo.br/scielo.php?script=sci_arttext\&pid=S0104-116 92009000400016\&lng=pt\&nrm=iso\&tlng=pt

14. Ortiz GF, Fernández AR. Utilización del servicio de urgencias en un hospital de especialidades. Cir Cirujanos. 2000;68(4):164-8.

15. Martins HM, Cuña LM, Freitas P. Is Manchester (MTS) more than a triage system? A study of its association with mortality and admission to a large Portuguese hospital. Emerg Med J. 2009;26(3):183-6.

16. Grouse AI, Bishop RO, Bannon AM. The Manchester Triage System provides good reliability in an Australian emergency department. Emerg Med J. 2009;26(7):484-6.

17. Van Der Wulp I, Van Baar ME, Schrijvers AJ. Reliability and validity of the Manchester Triage System in a general emergency department patient population in the Netherlands: results of a simulation study. Emerg Med J. 2008;25(7):431-4.

18. Cooke MW, Jinks S. Does the Manchester triage system detect the critically ill? J Accid Emerg Med. $1999 ; 16(3): 179-81$. 